\title{
Comunicação
}

[Communication]

\section{Ocorrência de Amblyomma aureolatum (Pallas, 1772) e A. ovale (Kock, 1844) (Acari: Ixodidae) parasitando Alouatta clamitans Cabrera, 1940 (Primates: Atelidae) na região norte do estado de Santa Catarina}

\author{
[Ocurrence of Amblyomma aureolatum (Pallas, 1772) and A. ovale (Kock, 1844) (Acari: Ixodidae) parasitizing \\ Alouatta clamitans Cabrera, 1940 (Primates: Atelidae) in the North of Santa Catarina State, Brazil]

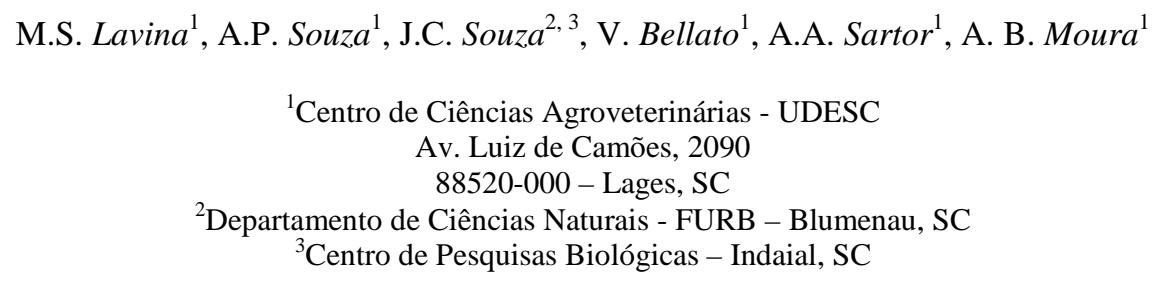

O gênero Amblyomma apresenta aproximadamente 106 espécies de carrapatos em todo o mundo. Destas, 33 podem ser encontradas no Brasil, parasitando aves, mamíferos, répteis e anfíbios. A espécie Amblyomma aureolatum ocorre na Argentina, Brasil, Guiana Francesa, Paraguai, Suriname e Uruguai. Os adultos parasitam carnívoros, e os ínstares imaturos aves e roedores. A. aureolatum encontra-se amplamente distribuída no Brasil, tendo sido observada parasitando o cão, a cabra, o boi, o gambá, o veado, a capivara, o quati e vários canídeos silvestres (Flechtmann, 1990). É bastante comum no cão, sendo a espécie mais frequente nesse hospedeiro no estado do Paraná (Ribeiro, 1970/1971). A espécie A. ovale é encontrada em boa parte dos países das Américas Latina e Central, com relatos de sua ocorrência também na região neártica. É uma espécie próxima a $A$. aureolatum, parasitando também carnívoros e vários outros hospedeiros na fase adulta. Os estágios imaturos parasitam principalmente roedores, tendo sido encontrados também em carnívoros.

De acordo com Flechtmann (1990), A. ovale é uma espécie comum dos animais selvagens no Brasil (onças, cervídeos, quatis, raposas, antas, etc.) e, com o tempo, adaptou- se aos cães domésticos nas zonas rurais, sendo hoje um dos carrapatos comuns nesses animais. Diferentes espécies do gênero Amblyomma são encontradas em áreas rurais parasitando cães que têm acesso a áreas de matas e florestas (Massard et al., 1981; Labruna et al., 2000). Na região Sudeste, as espécies de Amblyomma mais frequentemente encontradas em cães de áreas rurais são $A$. aureolatum, A. ovale e A. cajennense (Massard et al., 1981). Na região Sul, destacam-se as espécies $A$. tigrinum e $A$. aureolatum, embora pelo menos outras quatro espécies de Amblyomma já tenham sido relatadas em cães (Freire, 1972). Na região Norte, a espécie $A$. oblongoguttatum foi relatada como a de maior ocorrência, seguida por A. ovale e A. cajennense (Labruna et al., 2000).

A espécie Alouatta clamitans distribui-se desde Minas Gerais até o Rio Grande do Sul e, ainda, por uma faixa restrita na província de Missiones, na Argentina (Gregorim, 2006). A espécie já foi considerada ameaçada de extinção pelo decreto $\mathrm{n}^{\mathrm{o}}$ 1522/89 do IBAMA e pelo decreto $\mathrm{n}^{-0}$ 42.838, de 04/02/98 (IBAMA, 1998), do estado de São Paulo, mas, segundo a "Red List of Threatened Species” (Iucn, 2006), os bugios-ruivos são classificados como próximos de extinção. Assim como para a grande maioria das espécies silvestres, as principais ameaças são as perdas de habitat, o tráfico e a caça.

Recebido em 11 de abril de 2010 
Este trabalho foi realizado com o objetivo de relatar o parasitismo por $A$. aureolatum e $A$. ovale em bugios-ruivos (A. clamitans) nos municípios de Indaial (latitude 2653' Sul; longitude 49¹3' Oeste), Blumenau (latitude 265' Sul; longitude $49^{\circ} 03^{\prime}$ Oeste), Garuva (latitude $26^{\circ} 01^{\prime}$ Sul; longitude $48^{\circ} 51^{\prime}$ Oeste) e Jaraguá do Sul (latitude $26^{\circ} 29^{\prime}$ Sul; longitude $49^{\circ} 04^{\prime}$ Oeste). O material foi coletado no Criadouro Científico do Centro de Pesquisas Biológicas de Indaial, localizado na cidade de Indaial, Santa Catarina. O Centro possui um estudo de longo prazo, o Projeto Bugio, que realiza pesquisas nas áreas de comportamento, ecologia e saúde em ambiente natural e em cativeiro, desde 1991. O criadouro científico (IBAMA $\left.n^{\circ} 1 / 42 / 98 / 000708-90\right)$ recebe animais oriundos de apreensões efetuadas pelo IBAMA ou pela Polícia Ambiental, ou ainda espécimes encaminhados por zoológicos. Entre os meses de novembro de 2005 e dezembro de 2007, cinco bugios-ruivos (três fêmeas e dois machos) foram recebidos no criadouro com parasitismo por carrapatos. Os indivíduos vieram dos municípios de Indaial, Blumenau, Garuva e Jaraguá do Sul. O material coletado foi acondicionado em álcool $95^{\circ} \mathrm{GL}$ e depositado na coleção de material biológico de bugios-ruivos do CEPESBI (deliberação CGEN - MMA $\mathrm{n}^{\mathrm{o}}$ 196) e posteriormente enviado para a coleção de ixodídeos do Laboratório de Parasitologia e Doenças Parasitárias do Centro de Ciências Agroveterinárias (CAV) da Universidade do Estado de Santa Catarina.

Para a identificação dos ixodídeos, utilizou-se a chave dicotômica de Barros-Battesti et al. (2006). Na comparação dos exemplares com as informações contidas na chave, chegou-se às espécies A. aureolatum e A. ovale. Foram identificados 16 exemplares, nove em estágio adulto (seis fêmeas e três machos) e sete ínstares imaturos (três larvas e quatro ninfas). Foram identificados dois machos e uma fêmea de $A$. aureolatum e um macho e cinco fêmeas de $A$. ovale. A espécie A. aureolatum tem como características essenciais para identificação a presença, na coxa I, de espinhos longos, subiguais e contíguos, maiores que 0 comprimento do artículo, o externo terminando em ponta reta (Fig. 1a); o escudo é castanhoclaro com predomínio do amarelo-dourado (Fig. 2a); o sulco marginal alcança o segundo festão e o hipostômio tem dentição 3/3. Para A. ovale, a descrição é praticamente a mesma, porém nessa espécie o espinho externo é ligeiramente encurvado para fora e pouco mais longo que o interno (Fig. 1b); e o escudo se caracteriza por ser castanho com manchas acobreadas a esverdeadas (Fig. 2b). Amblyomma sp. e $A$. cajennense foram identificados em $A$. caraya capturados em resgate de fauna (Labruna et al., 2002). No Rio Grande do Sul, Brasil, em levantamento da fauna ixodológica, realizado por Freire (1972), foram identificados nos cães nove espécies de carrapatos: Amblyomma tigrinum, $A$. ovale, A. aureolatum (= A. striatum), $A$. cajennense, A. maculatum, A. humerale, A. incisum, Boophilus microplus e Rhipicephalus sanguineus. Martins et al. (2006), no mesmo estado, na cidade de Cachoeira do Sul, relataram a presença de $A$. aureolatum parasitando uma espécie de bugio, Alouatta guariba. Massard et al. (1981), ao estudarem as parasitoses de cães, no período 1976-1980, no Rio Grande do Sul e em alguns outros estados brasileiros, como Rio de Janeiro, Espírito Santo e São Paulo, verificaram que os cães dessas regiões eram parasitados, quando criados em áreas rurais, pelos carrapatos $A$. ovale, A. aureolatum, $A$. tigrinum e A. cajennense (exceto no Rio Grande do Sul); nas áreas urbanas, $R$. sanguineus foi a única espécie encontrada. Esta comunicação relata a presença de $A$. aureolatum e A. ovale parasitando bugios nas cidades de Indaial, Blumenau, Garuva e Jaraguá do Sul, em Santa Catarina. A parasitose pode ter associação com a constante permanência dos primatas no solo, visto que um dos animais estava ferido e outro era mantido em ambiente doméstico. 


\section{Lavina et al.}

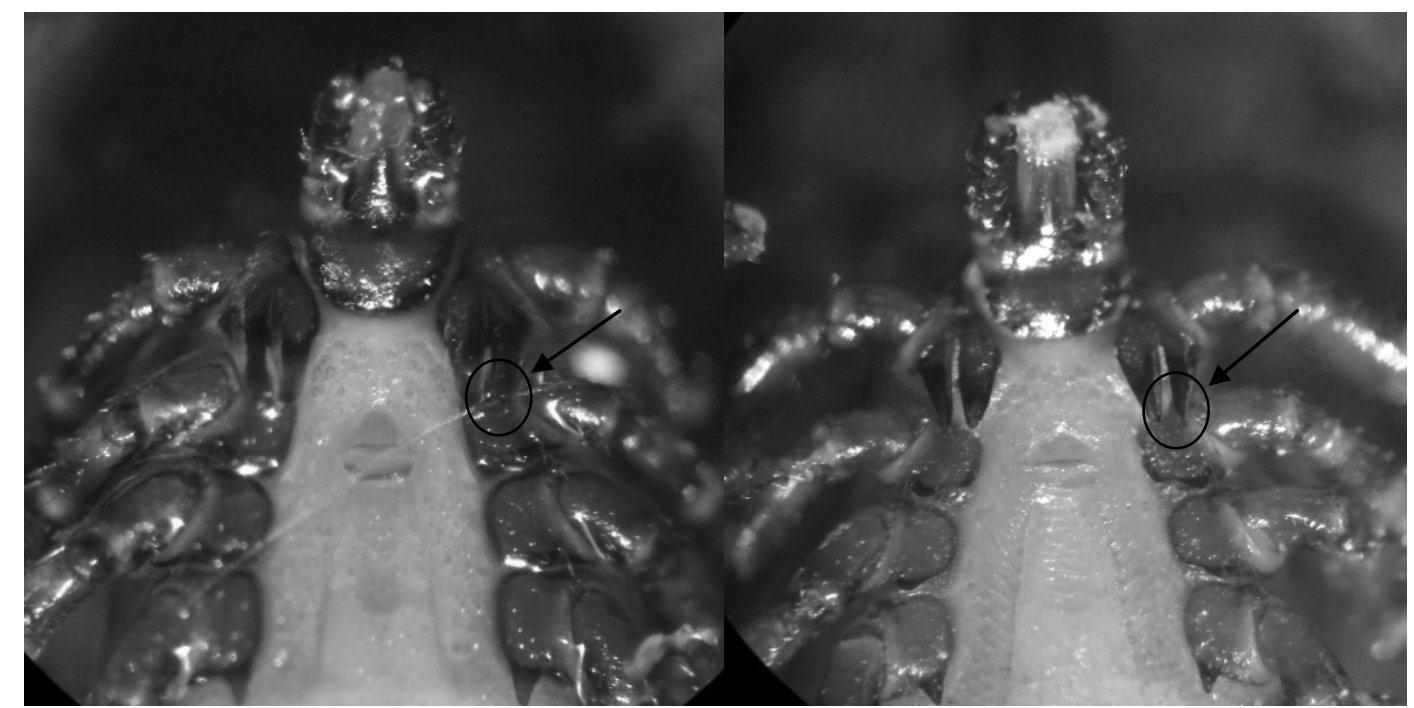

Figura 1. 1a- Macho de Amblyomma aureolatum. Em destaque a presença, na coxa I, de espinhos longos, subiguais e contíguos, maiores que o comprimento do artículo, e o externo terminando em ponta reta. 1bMacho de Amblyomma ovale. Em destaque a presença, na coxa I, de espinhos longos, subiguais e contíguos, sendo o espinho externo ligeiramente encurvado para fora e mais longo que o interno.

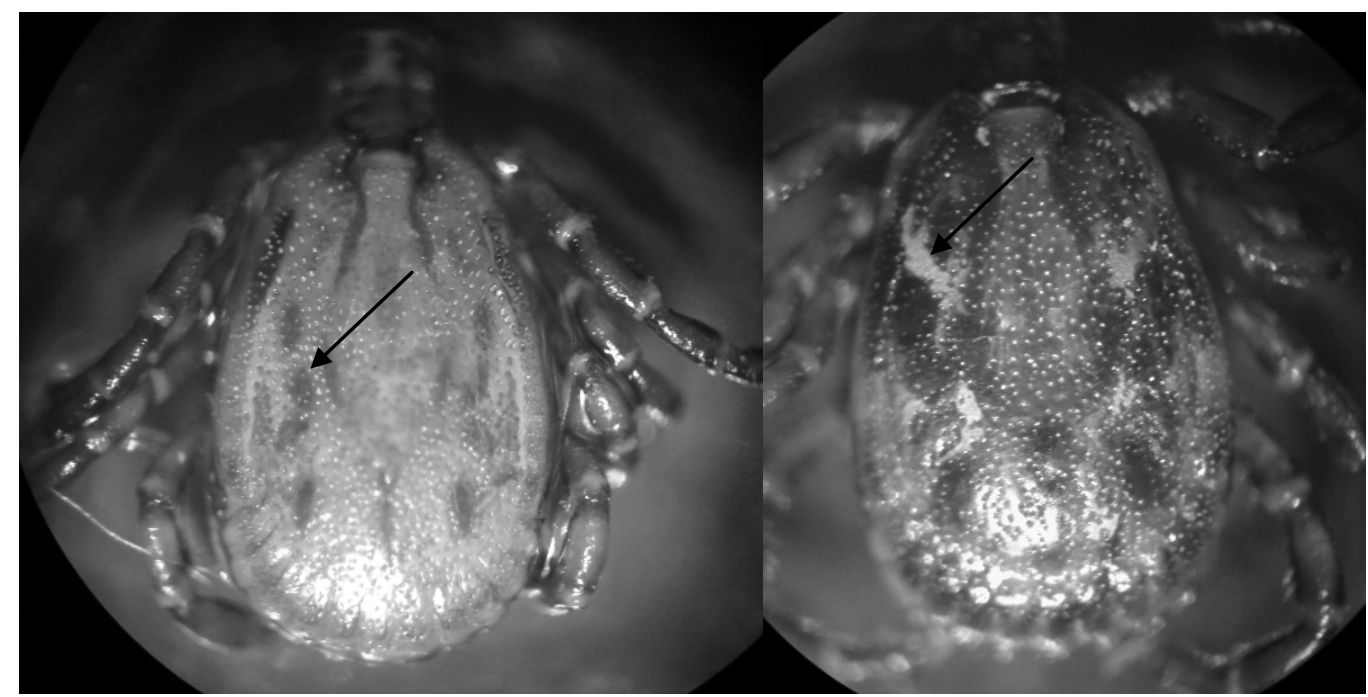

Figura 2. 2a- Macho de Amblyomma aureolatum, caracterizando o escudo castanho-claro com predomínio do amarelo-dourado. 2b- Macho de Amblyomma ovale, caracterizando o escudo castanho com manchas acobreadas a esverdeadas.

Palavras-chave: Amblyomma aureolatum, Amblyomma ovale, Alouatta clamitans

\section{ABSTRACT}

The authors confirm the presence of one female and two males of Amblyomma aureolatum and five females and one male of A. ovale parasitizing southern brown howler monkeys in the municipalities of Indaial, Blumenau, Garuva, and Jaraguá do Sul, Santa Catarina State, Brazil.

Keywords: Amblyomma aureolatum, Amblyomma ovale, Alouatta clamitans 


\section{REFERÊNCIAS BIBLIOGRÁFICAS}

BARROS-BATTESTI, D.M.; ARZUA, M.; BECHARA, G.H. et al. Carrapatos de importância médico-veterinária da região neotropical: um guia ilustrado para identificação de espécies. São Paulo: Vox/ICTTD-3/Butantan, 2006. 223p.

FLECHTMANN, C.A.W. Ácaros de importância médico-veterinária. 3.ed. São Paulo: Nobel, 1990. $192 \mathrm{p}$.

FREIRE, J.J. Revisão das espécies da família Ixodidae. Rev. Med. Vet., v.8, p.1-16, 1972.

GREGORIN, R. Taxonomia e variação geográfica das espécies do gênero Alouatta Lacépède (Primates, Atelidae) no Brasil. Rev. Bras. Zool., v.23, p.64-144, 2006.

IUCN. Red list of threatened species, 2006. Disponível em: <http://www.redlist.org/>. Acessado em: 10 fev. 2006.

LABRUNA, M.B.; HOMEN, U.S.F.; HEINEMANN, M.B. et al. Ticks (Acari: Ixodidae) associated with rural dogs in Uruará, Eastern Amazon-Brazil. J. Med. Entomol., v.37, p.774-776, 2000.
LABRUNA, M.B.; WHITWORTH, M.C.; HORTA, D.H. et al. Life cycle and host specificity of Amblyomma triste (Acari: Ixodidae) under laboratory conditions. Experimental Applied Acarology, v.26, p.115125, 2002.

MARTINS, J.R.; SALOMÃO, E.L.; DOYLE, R.L. et al. First record of Amblyomma aureolatum (Pallas, 1772) (Acari: Ixodidae) parasitizing Alouatta guariba (Humboldt, 1812) (Primata: Atelidae) in Southern Brazil. Rev. Bras. Parasitol. Vet., v.15, p.203-205, 2006.

MASSARD, C.A.; MASSARD, C.L.; REZENDE, H.E.B. et al. Carrapatos de cães em áreas urbanas e rurais de alguns estados brasileiros. In: CONGRESSO BRASILEIRO DE PARASITOLOGIA, 6., 1981, Belo Horizonte. Anais... Belo Horizonte: SBP. p.201, 1981.

RIBEIRO, S.S. Ixodídeos encontrados no cão doméstico no estado do Paraná. An. Fac. Med. UFPar, v.13/14, p.61-67, 1970/71. 